\title{
The Role of Drinking Places in Enhancing Risky Sexual Behaviours and the Spread of HIV/AIDS amongst the Tiv People of Benue State, Central Nigeria
}

\author{
Timiun, Godwin Aondohemba ${ }^{1,2, *}$, Timothy Scrase ${ }^{1}$ \\ ${ }^{1}$ Department of Sociology, School of Arts (Victoria), Australian Catholic University, Melbourne, Australia \\ ${ }^{2}$ Department of Sociology, Faculty of Social Sciences, Benue State University, Makurdi, Nigeria
}

Copyright $\subset 2017$ by authors, all rights reserved. Authors agree that this article remains permanently open access under the terms of the Creative Commons Attribution License 4.0 International License

\begin{abstract}
In 2013, the prevalence and incidence rates of HIV/AIDS infection in Nigeria were 3,229,757 and 220,394 respectively. Despite the fact that the influence of alcohol consumption on unsafe sexual behaviours and HIV risk in Nigeria has been documented, gaps still exist in knowledge on the roles of drinking places. This paper examines the roles of drinking places in enhancing illicit, risky sexual behaviours (irregular condom use and having sex while drunk) and the spread of HIV. A sample of 1,621 (864 women; 757 men; 815 HIV seropositive; 806 HIV seronegative) respondents who participated in survey and in-depth interviews were selected from 2 clinics and 2 other locations using multi-stage and purposive sampling methods. SPSS (version 21) software was used for quantitative data analysis. Drinking places are meeting points for lovers, alcohol consumption, verbal pornography and negotiations for illicit sexual activities with high risk of HIV infection. Understanding, and then addressing the impact of drinking places on risky sexual behaviours would assist in reducing the spread of HIV/AIDS amongst the Tiv people. Consequently, there likely would be an improvement in the sexual wellbeing of individuals and the public in Nigeria more generally.
\end{abstract}

Keywords Drinking Places, Risky Sexual Behaviours, HIV/AIDs, Nigeria

\section{Introduction}

In 2013, the prevalence and incidence rates of human immunodeficiency virus/ acquired human immune deficiency syndrome (HIV/AIDS) infection in Nigeria were $3,229,757$ and 220,394 respectively [1]. The sero-prevalence rate of HIV amongst 200 individuals, both male and female prospective blood donors at the University College Hospital,
Ibadan, Nigeria was $17.5 \%$ [2] while the rate amongst another group of 427 prospective blood donors, including men and women, at Benin Teaching Hospital was 47.5\% [3]. Due to the high incidence rate of HIV infection in the country, there has been an upswing in the desire to examine distal factors to ascertain their contribution to the problem. Scholars who have examined the influence of alcohol on risky sexual behaviours in Nigeria $[4,5]$ and elsewhere $[6,7$, $8,9,10]$ have not considered drinking places as a component of their study. This paper examines the role of drinking places in enhancing risky sexual behaviours and the spread of HIV in Nigeria.

Despite the fact that scholars have identified the relationship between alcohol consumption, risky sexual behaviours and vulnerability to HIV infection, the contribution of some of the activities at drinking places, such as selection of potential sexual partners, negotiations for sexual intercourse, and verbal pornography (sex talk) to unsafe sexual behaviours remains undocumented. Tumwesigye et al. [6] report that both men and women in Uganda do engage in sexual intercourse while drunk; $12 \%$ of men and $16 \%$ of women who had drunk alcohol in Uganda, were intoxicated before engaging in sexual intercourse. Amongst these groups, $78 \%$ of women said their partners were also intoxicated. While most of the women had sex with regular partners, most of the men had unprotected sex with non regular partners.

Further, another study in Nigeria reports how farmers in Taraba State would stay behind after the closure of the markets, to expend the proceeds from sales of agricultural commodities on alcohol with young women below the age of 30 years and also engage in unprotected sex with them. These behaviours have contributed to the high rate of HIV infection (7\%) in Taraba State [see 4]. There are also similar findings on the impact of alcohol consumption on high risk sexual behaviours in, for example, the USA [7, 8, 9, 10], and amongst college students in Nepal $[11,12]$. 
However, the activities that take place at drinking joints are critical to the understanding of the association between alcohol consumption, unsafe sexual behaviours (irregular condom use and engaging in intercourse while drunk) and HIV risk on one hand, and patronising drinking places, unsafe sexual behaviours and HIV risk on the other. The motivation for this paper is to provide such information especially in Nigeria, where the incidence rate of HIV is still high and knowledge is therefore required concerning the structural factors influencing the spread of HIV.

An average drinking environment (bars, clubs, open markets, in parks, and restaurants) in the study area has drinks (alcohol and non-alcohol), fried or cooked meat, music (stage performance or musical instruments) and hawkers selling different articles. With such a plethora of activities, people go to drinking places not necessary to drink but also for many other reasons. These places turn out to be meeting points for lovers who may be candidates for risky sexual intercourse.

It should be noted that drinking places may enhance the capacity of individuals, especially those who can afford it, to either eat meat or drink alcohol or both, listen to verbal pornography, negotiate for sex and sometimes indulge in risky sexual intercourse with non-regular partners while drunk. In addition, those who are looking forward for sexual relationships as a means of satisfying other needs may exhibit weak capacity to resist sexual overtures initiated at the drinking venues. These drinking places do not support safer sexual behaviours due to the manner of things that pervade the environments. Hence drinking places may be contributors to illicit risky sexual intercourse and continuous high incidence rates of HIV in Nigeria [see 13].

\section{Quantitative Methods}

The research utilised both quantitative and qualitative methods. Both survey and in-depth interviews were conducted to obtain data for the research. The quantitative and qualitative data was nested, and the qualitative data was used for gaining further insight into the quantitative data. This mixed method technique is referred to as concurrent transformative strategy (either nested or concurrent triangulation). It ensures that better insight would be obtained from the qualitative data to provide deeper understanding of some findings from the quantitative data [14]. The multi-stage sampling method was used in selecting 1,601 respondents in four different locations ${ }^{\text {a }}$ (Mkar, Aliade, Udei and Jovkyundan which are towns and villages from Gboko, Gwer, Guma and Konshisha Local Government Areas of Tivland ${ }^{\mathrm{b}}$ respectively). An eight page questionnaire with closed and open ended questions (on background characteristics, patronage of drinking places, risky sexual behaviours, HIV, and drugs consumption) was used for data collection in the first stage. Face to face interviews were conducted with the respondents by the researcher (correspondent-author), with the aid of some research assistants. The questionnaires were pretested by conducting a mock data collection with 50 respondents before the actual data collection exercise. The internal consistency and reliability of the data collection instrument was very high. The quantitative data collection lasted for five months between April and August, 2014. Completed questionnaires were scrutinised in the field to ensure exactness of the recorded information. Thereafter, they were retrieved and stored in a well secured office, accessed by the researcher alone.

At the completion of data collection, the responses were coded and entered into Statistical Product and Service Solution (SPSS) version 21 software, which has provision for the Generalised Linear Regression with Cumulative Link, was used for the analysis of quantitative data [see 15]. The response variable, patronage of drinking joints is an ordinal variable, however, the data fit in better with multinomial rather than ordinal distribution.

\section{Qualitative Methods}

In this segment of data collection, purposive sampling was used in selecting 20 respondents (10 sero-positive; 10 sero-negatve) who participated in in-depth interviews. Five individuals were selected in each location. The interviews were conducted in Tiv language using a guide with questions on structural factors (patronage of drinking places, risky sexual behaviours and HIV, poverty, cultural factors, availability of hotel accommodation) which influence sexual behaviour. An audio recorder was used for recording the discussions during the in-depth interviews. The data were transcribed and analysed by the researcher following the principles of concurrent transformative strategy (either nested or concurrent triangulation). This ensured that a more thorough insight would be obtained from the qualitative data, providing a deeper understanding of some of the findings from the quantitative data. In other words, the findings from the qualitative data thereby provided deeper insight into the intricacies of illicit sexual behaviours at drinking places.

\section{Ethical Issues}

Application for Ethics clearance was sent to Australian Catholic University (ACU) Human Research Ethics Committee (HREC), and Ethics approval was given in March, 2014. The researcher has adhered completely to the ethical provisions of both the University and other regulatory bodies (Nigeria) involved in overseeing research involving human beings. The Ethics clearance from ACU was accepted by the Benue State University Ethics Committee for the conduct of this study. The research was conducted with integrity noting its responsibilities to all stakeholders. Both the consent to participate in the study and for the publication 
of the findings was obtained from the participants using ACU consent forms before data collection activities.

\section{Quantitative Data Research Findings}

With regard to gender, females are more likely to patronise drinking places $(53.6 \%)$ than males $(46.4 \%$, see Table 1), and women are $11 \%$ more likely than the men engage in risky illicit sexual behaviours. Age correlates with patronage of drinking joints $(\mathrm{P}=0.03$; $\mathrm{OR}=0.29$; CI $=.094-.892$ ). The older individuals are more likely to patronise drinking places than those who are younger (see Tables 2 and 6). Apart from the youngest age group (18-19yrs), the age groups 20-24yrs, 25-29yrs and 30-34yrs $(15.4 \%, 23.6 \%$, and $22.2 \%)$ respectively are more likely to patronise drinking places than the older age groups above 35 years (see Table 2). Further elucidation from qualitative data supports the view that younger people are more predisposed to patronising drinking places for sexual partners and entertainment, while the older individuals do so to while away time and also meet possible sexual partners. Approximately 53\% of those who strongly affirmed that the patronage of drinking places influences risky illicit sexual behaviour were married. Individuals of different relationship status patronise drinking places to meet with regular or potential lovers. In comparison with those who are married, those who are single are 4.3 times more likely to patronise drinking joints relative to cohabiting versus married individuals (the chances are 52 times more likely, see Tables 3 and 6).

Table 1. Respondents Sex by Influence of Drinking places on Risky Sexual Behaviours

\begin{tabular}{|c|c|c|c|c|c|c|}
\hline \multicolumn{7}{|c|}{ Influence of Drinking Places on Risky Sexual Behaviours } \\
\hline & $\begin{array}{c}\text { Strongly } \\
\text { disagree }\end{array}$ & Disagree & Agree & Strongly agree & Total & $\%$ \\
\hline Sex & $\%$ & $\%$ & $\%$ & $\%$ & & \\
\hline Male & 51.5 & 51.8 & 45.7 & 46.4 & 749 & 46.8 \\
\hline Female & 48.1 & 48.2 & 54.3 & 53.6 & 852 & 53.2 \\
\hline Total & 54 & 164 & 806 & 577 & 1601 & 100 \\
\hline$\%$ & 100 & 100 & 100 & 100 & & \\
\hline
\end{tabular}

Note. The source of data is from field survey, 2014

Table 2. Age by patronage of Drinking Places and Risky Sexual Behaviours

\begin{tabular}{|c|c|c|c|c|c|c|}
\hline \multicolumn{7}{|c|}{ Influence of Drinking Places on Risky Sexual Behaviours } \\
\hline & $\begin{array}{c}\text { Strongly } \\
\text { disagree }\end{array}$ & Disagree & Agree & Strongly agree & Total & $\%$ \\
\hline Age & $\%$ & $\%$ & $\%$ & $\%$ & & \\
\hline $18-19 y \mathrm{yrs}$ & 9.3 & 11.6 & 11.2 & 8.5 & 163 & 10.2 \\
\hline $20-24 y r s$ & 27.8 & 18.9 & 19.8 & 15.4 & 293 & 18.3 \\
\hline $25-29 \mathrm{yrs}$ & 14.8 & 17.7 & 21.0 & 23.6 & 342 & 21.4 \\
\hline $30-34 \mathrm{yrs}$ & 24.1 & 18.5 & 20.2 & 22.2 & 336 & 21.0 \\
\hline $35-39 y r s$ & 7.4 & 6.1 & 6.7 & 9.0 & 120 & 7.5 \\
\hline $40-44 \mathrm{yrs}$ & 5.6 & 6.1 & 8.6 & 9.4 & 136 & 8.5 \\
\hline $45-49 y r s$ & 3.7 & 10.4 & 6.2 & 5.0 & 98 & 6.1 \\
\hline $50-54 \mathrm{yrs}$ & 5.6 & 6.7 & 4.1 & 3.5 & 67 & 4.2 \\
\hline $55-59 y \mathrm{yrs}$ & 1.9 & 2.4 & 2.0 & 2.4 & 35 & 2.2 \\
\hline $60+$ & 0.0 & 0.6 & 0.5 & 1.0 & 11 & 0.7 \\
\hline Total & 54 & 164 & 806 & 577 & 1601 & 100 \\
\hline$\%$ & 100 & 100 & 100 & 100 & & \\
\hline
\end{tabular}

Note. The source of data is from field survey, 2014 
Table 3. Relationship Status by Patronage of Drinking Places and Risky Sexual Behaviours

\begin{tabular}{|c|c|c|c|c|c|c|}
\hline \multicolumn{7}{|c|}{ Influence of Drinking Places on Risky Sexual Behaviours } \\
\hline Strongly disagree & & disagree & Agree & Strongly agree & Total & $\%$ \\
\hline Relationship status & $\%$ & $\%$ & $\%$ & $\%$ & & \\
\hline Married & 61.1 & 54 & 48.8 & 52.7 & 820 & 51.2 \\
\hline Single & 29.9 & 34.8 & 34.8 & 30.3 & 527 & 32.9 \\
\hline Widowed & 3.7 & 6.1 & 8.6 & 7.3 & 123 & 7.7 \\
\hline Divorced & 1.9 & 1.2 & 3.8 & 4.3 & 59 & 3.7 \\
\hline Separated & 3.7 & 3.0 & 3.7 & 4.9 & 65 & 4.1 \\
\hline Cohabiting & 0.0 & 0.0 & 0.5 & 0.5 & 7 & 0.4 \\
\hline Total & 54 & 164 & 806 & 577 & 1601 & 100 \\
\hline$\%$ & 100 & 100 & 100 & 100 & & \\
\hline
\end{tabular}

Note. The source of data is from field survey, 2014

Table 4. Educational Levels by Patronage of drinking Places and Risky Sexual Behaviours

\begin{tabular}{|c|c|c|c|c|c|c|}
\hline \multicolumn{7}{|c|}{ Influence of Drinking Places on Risky Sexual } \\
\hline & Strongly disagree & Disagree & Agree & Strongly agree & Total & $\%$ \\
\hline Education Levels & $\%$ & $\%$ & $\%$ & $\%$ & & \\
\hline No schooling & 14.8 & 4.9 & 7.9 & 7.3 & 122 & 7.6 \\
\hline Primary & 14.8 & 9.1 & 10.3 & 14.2 & 188 & 11.7 \\
\hline Secondary & 44.4 & 53.7 & 48.5 & 44.7 & 761 & 47.5 \\
\hline Tertiary & 25.9 & 32.3 & 33.3 & 33.8 & 530 & 33.1 \\
\hline Total & 54 & 164 & 806 & 577 & 1601 & 100 \\
\hline$\%$ & 100 & 100 & 100 & 100 & & \\
\hline
\end{tabular}

Note. The source of data is from field survey, 2014

Table 5. Monthly Income in Naira by patronage of Drinking Places and Risky Sexual Behaviours

\begin{tabular}{|c|c|c|c|c|c|c|}
\hline \multicolumn{7}{|c|}{ Drinking Joints Influence on Risky Sexual Behaviours } \\
\hline & Strongly disagree & Disagree & Agree & Strongly agree & Total & $\%$ \\
\hline Monthly income & $\%$ & $\%$ & $\%$ & $\%$ & & \\
\hline Less than 25000 & 72.2 & 73.8 & 74.9 & 73.1 & 1186 & 16.6 \\
\hline $25000-49000$ & 20.4 & 20.1 & 18.0 & 17.0 & 267 & 32.8 \\
\hline $50,000-99000$ & 7.4 & 3.7 & 6.1 & 6.8 & 98 & 6.1 \\
\hline $100,000+$ & 0.0 & 2.4 & 1.0 & 3.1 & 30 & 1.9 \\
\hline Total & 54 & 164 & 806 & 577 & 1601 & 100 \\
\hline$\%$ & 100 & 100 & 100 & 100 & & \\
\hline
\end{tabular}

Note. The source of data is from field survey, 2014. 
The Role of Drinking Places in Enhancing Risky Sexual Behaviours and the Spread of HIV/AIDS amongst the Tiv People of Benue State, Central Nigeria

Table 6. Correlates of Patronage of Drinking Places and Risky Sexual Behaviours

\begin{tabular}{|c|c|c|c|c|c|c|}
\hline \multirow{2}{*}{ Patronage of Drinking Places } & \multirow{2}{*}{ B } & \multicolumn{2}{|c|}{ Test of hypothesis } & \multirow{2}{*}{$\operatorname{Exp}(B)$} & \multicolumn{2}{|c|}{ 95\% Confidence Interval for $\operatorname{Exp}(\mathrm{B})$} \\
\hline & & $\mathrm{df}$ & Sig. & & Lower & Upper \\
\hline Strongly disagree & -3.755 & 1 & .000 & .023 & .007 & .075 \\
\hline Disagree & -2.234 & 1 & .000 & .107 & .034 & .337 \\
\hline Agree & .268 & 1 & .646 & 1.308 & .417 & 4.105 \\
\hline Sex (Male) & -.117 & 1 & .254 & .890 & .728 & 1.088 \\
\hline \multicolumn{7}{|l|}{ Age } \\
\hline $18-19 \mathrm{yrs}$ & -1.082 & 1 & .066 & .339 & .107 & 1.073 \\
\hline $20-24 \mathrm{yrs}$ & -1.239 & 1 & .031 & .290 & .094 & .892 \\
\hline $25-29 y r s$ & -.777 & 1 & .172 & .460 & .151 & 1.401 \\
\hline $30-34 y r s$ & -.882 & 1 & .120 & .414 & .136 & 1.259 \\
\hline $35-39 \mathrm{yrs}$ & -.652 & 1 & .263 & .521 & .166 & 1.633 \\
\hline $40-44 \mathrm{yrs}$ & -.686 & 1 & .238 & .504 & .161 & 1.573 \\
\hline $45-49 \mathrm{yrs}$ & -1.241 & 1 & .034 & .289 & .092 & .910 \\
\hline $50-54 \mathrm{yrs}$ & -1.282 & 1 & .032 & .277 & .086 & .897 \\
\hline $55-59 \mathrm{yrs}$ & -.637 & 1 & .315 & .529 & .152 & 1.834 \\
\hline \multicolumn{7}{|l|}{ Education } \\
\hline No schooling & -.222 & 1 & .279 & .801 & .535 & 1.198 \\
\hline Primary & .179 & 1 & .294 & 1.196 & .856 & 1.672 \\
\hline Secondary & -.133 & 1 & .233 & .876 & .704 & 1.089 \\
\hline \multicolumn{7}{|l|}{ Relationship status } \\
\hline Single & .042 & 1 & .697 & 1.043 & .842 & 1.292 \\
\hline Cohabiting & .422 & 1 & .418 & 1.526 & .549 & 4.239 \\
\hline \multicolumn{7}{|l|}{ Condoms use(last six months) } \\
\hline Did not use & .401 & 1 & .167 & 1.494 & .845 & 2.640 \\
\hline Used sometimes & -.041 & 1 & .742 & .960 & .751 & 1.226 \\
\hline Used always & -.006 & 1 & .970 & .994 & .720 & 1.371 \\
\hline \multicolumn{7}{|l|}{ HIV status } \\
\hline Positive & -.109 & 1 & .286 & .897 & .734 & 1.096 \\
\hline \multicolumn{7}{|l|}{ Had sex while drunk } \\
\hline Yes & -.123 & 1 & .311 & .884 & .697 & 1.122 \\
\hline No & -.462 & 1 & .002 & .630 & .468 & .848 \\
\hline Number of Sexual partners & .417 & 1 & .000 & 1.517 & 1.299 & 1.772 \\
\hline
\end{tabular}

Note: The source of data is from field survey, 2016.

Furthermore, approximately $34 \%$ of those who strongly affirmed that patronage of drinking places contributes to the problem of risky sexual behaviours have completed tertiary education. In comparison with tertiary level of education, those without formal education are 19.9 times less likely to patronise drinking places relative to secondary versus tertiary levels of education (the chances are $12.4 \%$; less likely, see Tables 4 and 6). Similarly, 3.1\% of those who strongly affirmed that patronage of drinking places contribute to the problem of illicit risky sexual behaviours belong to high income group who earn more than 100,000 Nigerian Naira per month (see Table 5). With regard to HIV status, those who are HIV positive are 10 times less likely to patronise drinking places relative to those who are HIV negative. Several factors such as stigma and poverty may be responsible for this observation [see 16].

Further still, the numbers of sexual partners correlates with the patronage of drinking places $(\mathrm{P}=0.000 ; \mathrm{OR}=1.52$; $\mathrm{CI}=1.299-1.772$ ). The higher the number of sexual partners the more likely the patronage of drinking joints and risky, illicit sexual behaviour. For example, in comparison with those who had never used condom, those who did not use condoms in the last six months preceding the study are 49 times more likely to patronise drinking places relative to those who use condoms always as opposed to those who had never used condoms. Similarly, in comparison with those who had never used alcohol, those who had sex while drunk are 11.6 times less likely to patronise drinking places relative 
to those who 'did not have sex while drunk' versus had never used alcohol (chances are 37 times less likely).

\section{Qualitative Data Research Findings}

As stated elsewhere, drinking places have a plethora of activities taking place within their vicinity. Some individuals go to such places not necessarily to drink but also for other reasons. These places turn out to be meeting points for lovers, especially young adults. One of the respondents said:

Drinking places are the easiest places to meet
people and talk with them. The women also know
this, so if they want to talk to a man but they are
finding it difficult, they go to the drinking places
especially if the person drinks. They meet the
person there and chat. Most often when people
drink, they forget themselves and can do anything.
It has increased the problem of infidelity. (Female,
21 years; single)

Corroborating what this participant has said, another individual point out that prospective sexual partners meet at drinking joints, share some drinks together, negotiate and then engage in sex later. This is aptly captured in her statement:

\begin{abstract}
In drinking places, the man will offer the woman drinks and, later, the man will call the woman by the side, and say "I love you, all this while that I sat there, I am just admiring you; so I want to tell you something". Then the woman will pretend as if she does not know what the man wants, but as the man continues to talk everything will go well (Female, 22 years; married).
\end{abstract}

Further, drinking places have made it easier for people to meet potential sexual partners and negotiate multiple sexual relationships, thus aggravating the problem of unsafe sexual behaviours. One of the participants described the issue thus:

Beer parlours have increased the rate of infidelity. People who find it difficult to meet the opposite sex take the opportunity of utilising beer parlours and hotels. Some ladies will dress in trousers that are cut in four sections and sit at beer parlours waiting for men to buy fried fish and beer for them. They will drink with this man and thereafter, another person, making love with them (Female, 30 years; married).

Furthermore, drinking joints are also places where individuals learn new things about sex; those who are drunk discuss issues of sex without restraint. A respondent said:

Each time I sit in drinking places, I hear men and women who have taken alcohol discuss issues of sex and so people learn new things about sex in such places. They don't have control when they are drunk, they say anything. This is also a serious problem (Female, 60 years; widow).

It is also important to note that some married individuals who patronise drinking places get into problems with their spouses which may lead to divorce. There are also instances where the scramble for girlfriends in these places leads to open confrontation and sometimes the death of an individual. One of the respondents reported that:

Drinking places are used by lovers in this place. Some women have been divorced as a result of this. Some men will come and carry a married woman to a drinking place, they will eat pepper soup and also get a room to rest; in doing all this, they forget themselves there, and when the woman comes back and meets her husband back at home, it becomes a serious problem and it often leads to divorce. Some men want to take another's girlfriend at a drinking place, which also leads to fighting and sometimes the death of someone (Male, 21 years, single).

\section{Sexual Capacity, Sexual Motivations and Performance}

Some individuals go to drinking places to look for sexual partners to satisfy their sexual urge or to satisfy some other needs. Those who are rich have a greater capacity to buy drinks, meat dishes, and other things for their partners. In contrast, those who are poor have a weaker capacity, therefore, they depend on those with stronger capacity to supply drinks, meat dishes and so forth. The desire to satisfy certain needs becomes a strong motivation for sex. Hence those who have stronger capacity have a stronger negotiating power for sex than the weaker ones. Women are more likely to engage in risky sexual behaviours than the men. A respondent says:

Drinking places are good for meeting women; when you go there, your parents and other people will think you have only gone there to drinks but you do other things as well. There are those who are selling meat, melon and other things. You buy something with them and also discuss issues of love. If it is a lady that drinks, you buy beer for her and sit together to drink. When you drink, you are no longer shy to request for something. This is what happens at these places. (Male, 27 years, married).

Drinking places receive less social attention in comparison with brothels, where they are known to be a hub for commercial sexual activities. Hence some people who would have gone to brothels for sex turn to drinking places as an alternative. Due to the ambience that pervades drinking 
environments, they do not support safer sexual performance or practices. The following statement supports the view that drinking places enhance the capacity of individuals to interact with sexual partners in similar ways to brothels:

\section{Drinking places have a lot of problems. When people sit and drink they like every women they see and it is the same with the women. Many people move from drinking places to places to have sex without using any protection (Female, 23 years, single).}

In another dimension, drinking places have increased the capacity of married individuals for infidelity.

\begin{abstract}
Some married men will say they want to go and rest at drinking places, meanwhile they have made an appointment with a woman to meet there. They will drink, eat and sometimes have sex, and then the man will come back home as if he has not done anything; even married women go there to meet men (Female; 32 years, married)
\end{abstract}

The general overbearing factor that weakens the capacity of an individual to resist sexual overtures in the area is poverty. The following statement supports this assertion:

\begin{abstract}
Many people are involved in infidelity because of poverty. For instance, women who don't have nice soap or face cream, and their husbands are not able to provide these things, sometimes resort to adultery to meet their (material) needs. I know many of them, but what we are saying here does not require calling names, otherwise, I would have called names. When I was a student, I did something like that (Male, 54 years, married).
\end{abstract}

\section{Discussion}

Previous studies conducted in some African countries have identified structural factors such as the influence of cultural norms on gender sexual roles [17, 18, 19], masculinity in sexual relationships $[20,21]$, poverty and commercial sex taking place in brothels [22, 23], as predictors of unsafe sexual behaviours and the spread of HIV. Other related studies have documented the impact of alcohol consumption on risky sexual behaviours in Nigeria $[4,5]$ and elsewhere $[6,7,8,9,10]$. Nevertheless, the beehive of activities taking place in drinking joints such as verbal pornography, dancing, buying of fried or roasted meat and drinks for others, which facilitate sexual negotiations and risky sexual behaviours has not been previously reported. This is especially the case in Nigeria, where such activities have contributed to an increase in risky sexual behaviours and possible HIV infection. Those who don't have money but wish to enjoy themselves visit these places to meet old or new friends who may be prospective sexual partners. These places provide opportunities for negotiation of sexual relationships. Apart from that, sexual matters are discussed freely by drunkards. Thus, beginners and even experienced individuals in dating practices increase their capacity for dating by learning new matters of interest. In addition, there are those who hold the belief that a local alcoholic drink known as Ogogoro gin increases the potency for sexual intercourse; hence there are individuals who drink Ogogoro with the sole motive of having sex, whilst others simply have sex while drunk. The cumulative effect of drinking places and Ogogoro consumption are multiple relationships with low levels of condom usage, and an increase in HIV infection. Women are more likely to engage in risky sexual behaviours than men due to their low capacity to negotiate for safer sex. Hence, these women have a higher chance of been infected with HIV than men. Addressing these issues would assist in scaling down unsafe sexual behaviours and HIV infection through sexual intercourse. The benefits would be an improvement in the sexual wellbeing of both the individuals and public.

\section{Conclusions}

Both the quantitative and qualitative findings support the assertion that patronage of drinking places has contributed to the problem of illicit sexual behaviours with a higher risk of HIV infection. There are joints for drinking of alcohol, meeting new sexual partners, negotiations for illicit sex, verbal pornography that increases the desire for sex, and open conflict due to scramble for sexual partners. Serial multiple partnerships with short gaps initiated at drinking places constitutes high risk, sexual behaviours, hence recently infected partners can expose the other to the danger of infection especially where probability of transmission are highest [24]. However, previous studies in Nigeria have not given attention to the contributions of these places to the problem of illicit sexual behaviours and a higher incidence of HIV infection in the study area, and the country at large.

The incidence rate of HIV infection will continue to be high in Nigeria if polices are not formulated to address structural factors such as drinking places where people meet sexual partners, eat meat or drink alcohol or both, listen to verbal pornography that increase the desire for sex, negotiate and sometimes indulge in sexual intercourse with high risk of HIV infection.

\section{Endnotes}

${ }^{\mathrm{b}}$ Tivland is divided into two major blocks- the Ipusu and Ichongu blocks. The Multi-Stage Area sampling method was used for obtaining respondents for quantitative data collection using the questionnaire, while purposive sampling was utilised to select respondents for qualitative data collection using in-depth interviews. One urban and one rural area were selected from each of the two blocks (four areas in all - two urban areas and two rural areas). One hospital was 
selected from each of the two blocks to sample people living with HIV/AIDS who come to the centers to collect Anti-retroviral drugs. The other segment of the sample was drawn amongst residents in the communities who were aware that they are not HIV positive.

A probability sampling without replacement (raffle draws) was used in selecting Gwer West (urban area) and Guma (rural area) from the homogeneous settlements of Ichongu block; while Gboko (uban area) and Konshisha (rural area) were selected from the Ipusu using the same method. General Hospital, Aliade was then selected from Gwer West while NKST Hospital, Mkar was selected from Gboko to obtain samples of those living with HIV. The table of random numbers was used in selecting Udei from Guma out of several other rural settlements such as Kaseyor, Yerwata, Ukohor, Umenga, Agasha, Daudu, Uluva, Yogbo etc. Similarly, Jovkyundan was selected from Konshisha out of other rural settlements such as Tse-Agberagba, Gungul, Korinya, Agbeede, Awajir, Tsuwe, Mbaakpur, Achoho, Iber, Akputu etc.

Sample size determination was guided by the formula $\beta=x^{2} \rho \varrho / d^{2}$

Where $x=$ standard normal deviation at $95 \%$, which is 1.96

$\rho=$ Proportion of partners in sexual exclusivity

relationship in previous studies; but Since search in literature has not yielded that proportion from study of this nature

$\rho \rho$, will be considered to be $50 \%$, which is 0.5

$$
\begin{aligned}
& \mathrm{q}=1-\rho \rho, \mathrm{d}=0.05 \text { level of precision } \\
& \quad \beta=1.96 \times 1.96 \times 0.5 \times 0.5 / 0.05 \times 0.05=384
\end{aligned}
$$

More than 384 respondents were selected from each of the four location as follows:

Urban-Ipusu - 411; Urban-Ichongu - 394; Rural-Ipusu 396; Rural-Ichongu - 400. It brings the total numbers of respondent to 1601 .

A sample size of 805 individuals were randomly selected using systematic sample method after the list of people living with HIV who attend clinic in the hospitals was obtained by the research team. The rest of the respondents (976) were sampled from their residences after the villages were selected using table of random numbers. Purposive sampling method was also used in selecting 20 respondents for in-depth interviews. All the respondents have tested for HIV at least once and had patronised drinking places for some reasons. The 976 respondents were sero-negative at the last time they tested for HIV.

${ }^{\mathrm{b}}$ The North Central Zone where Tivland is located has a population of 20,369,956 people while Benue State (Tivland) has 4,253,641 individuals. Thus the population of Benue State represents $21 \%$ of that of the North Central Zone and $3 \%$ of the population of Nigeria. Tiv people are predominantly farmers and are found originally in towns and villages in
Benue, Taraba, Nasarawa and Plateau States. Due to the position of the Tiv people as one of the largest groups in North Central Nigeria, and also as a link between northern and southern parts of Nigeria, the adjoining states have several things in common with them.

\section{Competing Interest}

The authors declare no conflict of interest.

\section{Funding}

Not applicable

\section{Authors' Contributions}

GAT was the researcher and writer. TS participated in drafting and word processing of the manuscript. All authors read and approved the manuscript.

\section{Consent to Publish}

Both the consent to participate in the study and for the publication of the findings was obtained from the participants using ACU consent form before data collection activities.

\section{Acknowledgements}

The authors acknowledge the financial support from Australian Catholic University to conduct HIV and Sexual Behaviour research in Nigeria. We also appreciate the anonymous reviewers for their useful comments. We thank Shikaan Tever, Amokaha Samuel, Ali Jennifer, Asom Nicholas, Kough Mbachie, Nyamshar Seember, Akpii Peter, Ngiyev Godwin, kohol Gladys, Iortyom Benedict and Faga Emmanuel who helped with data collection. Others are Tarhembe Joseph, Dyegh Cletus, Sati Saakaan, and Anchongu Emmanuel. Doris Timiun helped with data entry.

\section{REFERENCES}

[1] National Agency for the Control of AIDS (NACA), Federal Republic of Nigeria. Global AIDS response: country progress report (Nigeria GARPR) Abuja, Nigeria, 2012

[2] I.O.Okonko, F.O. Adeniji, P.O. Okerentugba, K.C. Anugweje, Detection of HIV 1 \& 2 antibodies among intending blood donors. Nature and Science; 10; 5(2012) 1-6

[3] J. O Dirisu et al., A Survey of prevalence of serum antibodies to human immunodeficiency deficiency virus (HIV), hepatitis 
$\mathrm{B}$ virus (HBV) and hepatitis $\mathrm{C}$ virus $(\mathrm{HCV})$ among blood donors. N Am J Med Sci 3;1 (2011) 35-38.

[4] E.D. Oruonye, An assessment of the response to the HIV/AIDS pandemic in Taraba State, Nigeria. Journal of Geography and Regional 4; 2 (2011) 104-109

[5] O. Azuonwu, O. Erhabor, N. Frank-Peterside, HIV Infection in Long-Distance Truck Drivers in a Low Income Setting in the Niger Delta of Nigeria. Journal of Community Health 36;4 (2011) 583-587. doi: 10.1007/s10900-010-9344-4

[6] N.M. Tumwesigye, R.K Wanyenze, T.K. Greenfield, Intoxication before last sexual intercourse and HIV risk behavior among men and women in Uganda: Evidence from a nationwide survey. Int J Alcohol Drug Res, 1;1 (2012) 17.

[7] H.E. Hutton, et al., The Relationship between Recent Alcohol Use and Sexual Behaviours: Gender Differences among STD Clinic Patients. Alcoholism, clinical and experimental research 32; 11 (2008) 2008-2015.

[8] R. Caetano, C.L Clark, Trends in alcohol consumption patterns among Whites, Blacks and Hispanics: 1984 and 1995. J Stud Alcohol 59 (1998) 659-68. 33.

[9] Raj, D. Reed, M.C. Santana, A.Y Walley, S.L. Welles, C.R. Horsburgh, et al. The associations of binge alochol use with HIV/STI risk and diagnosis among heterosexual African American men. Drug Alcohol Depend 101(2009) 101- 106.

[10] T. Irwin, J. Morgenster, J. Parson, M. Wainberg, E. Labouvie, Alcohol and sexual HIV risk behaviour among problem drinking men who have sex with men: an event level analysis of timeline follow back data. AIDS Behav. 10 (2006) 299307.

[11] Kanekar, M.Sharma, Determinats of safer sex behaviours among college students. Acta Didactica Napocensia 3;1(2010) 29-38

[12] R. Adhikari, J. Tamang, Premarital sexual behavior among male college students of Kathmandu, Nepal. BMC Public Health 9;241(2009) 1471-2458

[13] G.A Timiun, Sexual webs model for the examination of unsafe sexual behaviours and the spread of sexually transmitted diseases including HIV/AIDS. Asian Social Science 8; 7 (2012) doi:10.5539/ass.v8n7p119.

[14] M.R. Moore, Gendered power relations among women: a study of household decision making in Black, lesbians' stepfamilies. AM. Sociology Review 73 (2008): 335-56
[15] R .H. Heck, S.C. Thomas, \& L.N. Tabata, Multilevel Modelling of Categorical Outcomes Using IBM SPSS: Quantitative Methodology Series. Routledge, New York: Taylor \& Francis (2012)

[16] G. A. Timiun, T. Scrase "We don't want to be noticed collecting drugs': the effects of stigma and discrimination on adherence to medication amongst people living with HIV in Tiv Land, north central Nigeria. TUPED369. 21th International AIDS Society Conference (AIDS 2016) Durban, South Africa from 18-22 July 2016.

[17] M. Macia, P. Maharaj, \& A. Gresh, Masculinity and male sexual behaviour in Mozambique. Culture, Health \& Sexuality, 13:10 (2011), 1181-1192. doi:10.1080/13691058.2011.611537

[18] T.L. Mah, \& B. Maughan-Brown, Social and cultural contexts of concurrency in a township in Cape Town, South Africa. Culture, Health \& Sexuality, 15:2 (2012), 135-147. doi: $10.1080 / 13691058.2012 .745951$

[19] R. Jewkes, \& R Morrell, Gender and sexuality: emerging perspectives from the heterosexual epidemic in South Africa and implications for HIV risk and prevention. Journal of the International AIDS Society, 13, 6 (2010).

[20] Lynch, P.W Brouard, \& M. J. Visser, Constructions of masculinity among a group of South African men living with HIV/AIDS: reflections on resistance and change. Culture, Health \& Sexuality, 12:1 (2009) 15-27. doi: $10.1080 / 13691050903082461$

[21] G. E Siu, D. Wight, \& J. Seeley, 'Dented' and 'resuscitated' masculinities: the impact of HIV diagnosis and/or enrolment on antiretroviral treatment on masculine identities in rural eastern Uganda. Sahara j, 11 (2014) 211-221. doi:10.1080/17290376.2014.986516

[22] J. Munoz, A. Adedimeji, \& O. Alawode, 'They bring AIDS to us and say we give it to them': Socio-structural context of female sex workers' vulnerability to HIV infection in Ibadan, Nigeria. [Multi-center Study]. Sahara J, 7:2 (2010), 52-61.

[23] B. I Popoola, Occupational hazards and coping strategies of sex workers in southwestern Nigeria. Health Care Women Int, 34: 2 (2013), 139-149.

[24] C.H. Mercer, C.R.H Aicken, C. Tanton, C.S. Estcourt, M.G. Brook, F. Keane, et al. Serial monogamy and biologic concurrency: measurement of the gaps between sexual partners to inform targeted strategies. Am J Epidemiol. 178; 2 (2013)249-59. 